\title{
THE LAWRENGE-BIEDL SYNDROME.
}

\author{
BY
}

\author{
GWENVRON M. GRIFFITHS, Cheddleton.
}

OF recent years there have been reported in continental and American literature a number of cases showing an association of adiposity, polydactyly, retinitis pigmentosa and mental retardation, often among several members of a family. The descriptions given by various authors show a remarkable similarity, not only in the main features of the condition, but also in minor eharacteristics, and the case $I$ have to describe is typical in this respect.

\section{PERSONAL CASE.}

Helen H., age 5, was admitted as an imbecile. The family history on the father's side is negative. The mother is one of four children; her elder brother had two thumbs on one hand. She is plump, a tendency which runs in the family. She had six pregnancies(1) a girl, age 10, is normal mentally but has webbed toes on each foot; (2) a girl, also has webbed toes ; (3) a boy of 6 , quite normal ; (4) the patient ; (5) a boy, who died when 10 days old of bleeding from the nose, mouth, and rectum, and who had six fingers on each hand and six toes on each foot; (6) a boy, stillborn, with a deformed head.

The patient was a full-term child weighing 12 pounds and the mother says it was an easy confinement. Squint and nystagmus were noticed soon after birth. The child grew rapidly, but required no more feeding than others. She had two teeth at seven weeks. She started walking at two, but did not talk till four. The only illnesses were whooping cough and bronchitis.

She is a tall child with marked adiposity. Her height is $111 \mathrm{~cm} .(3 \mathrm{ft} .7 \mathrm{in}$.$) and weight$ $28 \mathrm{~kg}$. (4 st. $3 \mathrm{lb}$.). Her face is full but not puffy ; she has red cheeks and delicate features. The obesity is most marked round the mammæ, abdomen and thighs, lessening towards the extremities. The skin is soft, cold and glabrous, and the hands and feet tend to be blue and puffy. The hair of the head is fine and dry; there is very little on the body and the eyebrows are scanty. The head is large, with big parietal eminences, circum. ference $52.8 \mathrm{~cm}$. (21 in.). The fingers are tapering with incurving of the little finger, on the outer side of the proximal phalanx of each of which is a small fleshy mass. Each foot has six toes, with the second and third webbed. There is some genu valgum and flat foot. The heart and lungs are negative and reflexes are normal.

There is internal strabismus of the right eye, and nystagmus of the left. A condition of hemeralopsia is present. Objectively, a concentric diminution of the visual fields is apparent to rough testing. The discs are pale, with pigmentation round the right disc, but there is no typical retinitis pigmentosa.

Mentally the girl is lethargic, appears to take little interest, and often will not answer questions, though some of her voluntary remarks indicate that she takes more notice than is apparent. She will sit for hours looking at pictures, or will stand quite still doing nothing. She is emotionally labile, but usually placid and contented, with occasional outbursts of temper. She has no abnormal craving for food or drink, but has a good appetite. She is clean and tidy. 
Radiographic examination of the skull shows an abnormal outline with normal density of bone. The pituitary fossa is small with a high, somewhat thickened dorsum sellæ. The foot shows five metatarsals, but the fifth metatarsal articulates with two sets of phalanges. There is no bony syndactyly. The hand shows no bony outgrowth corres-

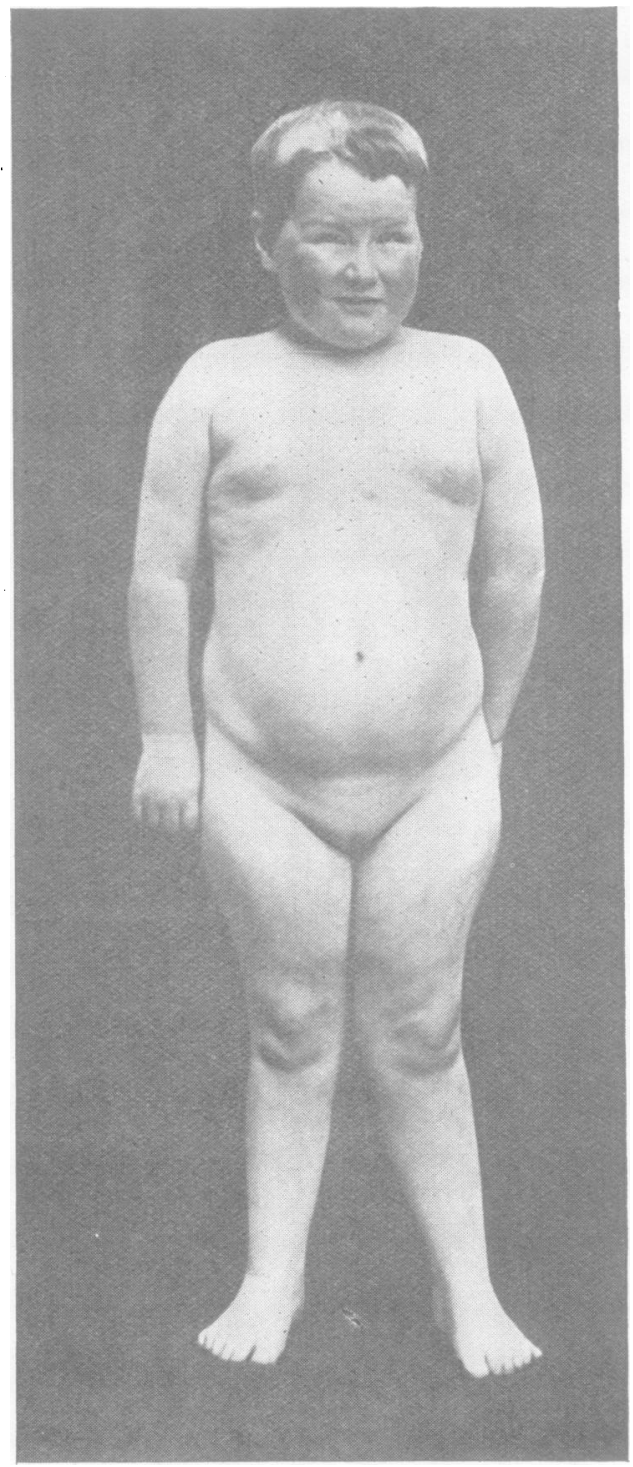

ponding to the sessile mass. The ossification of the carpus is that of a child of seven or eight.

The blood sugar curve shows a slight increase of tolerance. The urine is normal. Blood calcium is $13 \mathrm{mg}$. per 100 c.c. The blood count shows a mild leucocytosis with 
relative lymphocytosis. W.R. is negative. C'ushing's thermic reaction was tried; the injection of 1 c.c. of anterior pituitary preparation resulted in a rise of temperature of 1 degree, and three and a half hours later a rise of pulse rate from 80 to 110 , this lasting two hours.

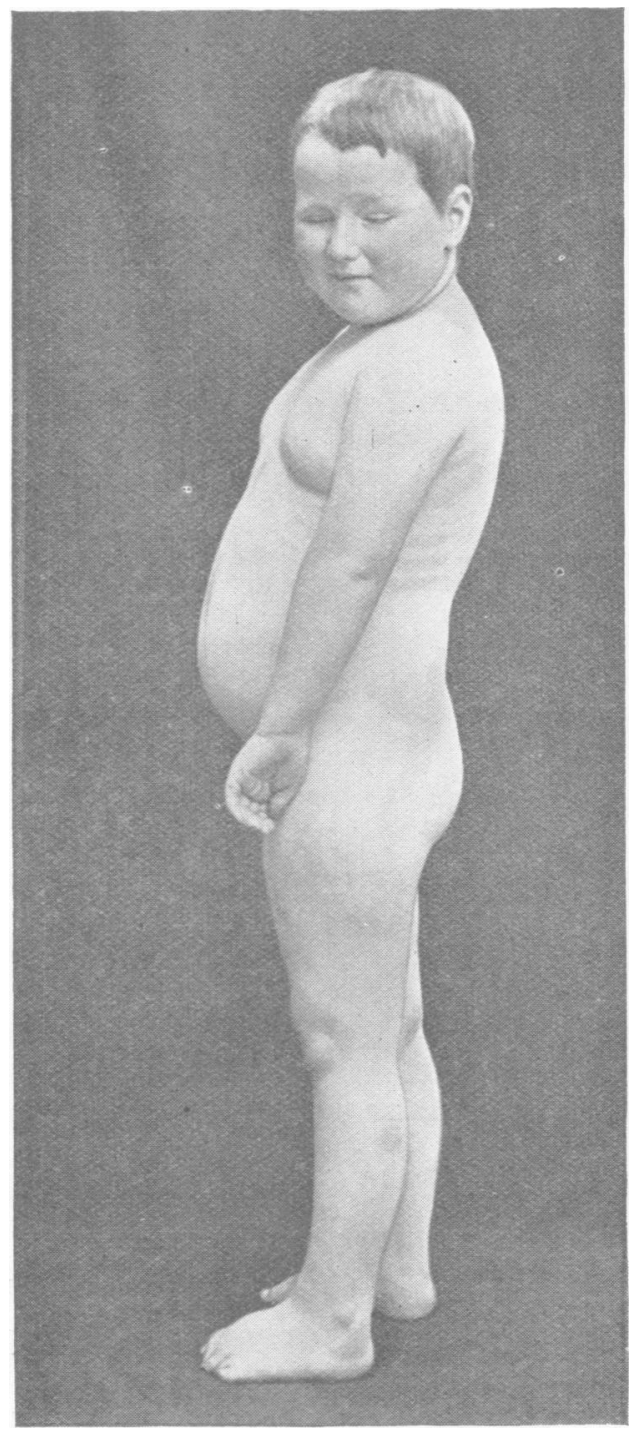

Thyroid treatment had no effect, and whole pituitary tablets have had no noticeable effect in six months. During this period the patient has grown $3 \mathrm{~cm}$., but the weight has been stationary. The second incisors have appeared. 


\section{DISGUSSION.}

The association of retinitis pigmentosa with polydactyly and other forms of congenital malformation has long been recognised, as has its familial character, so that the eye condition may be regarded as an inborn tendency to defect. In 1866 Lawrence and Moon described in four members of a family the occurrence of obesity, with genital underdevelopment, retinitis pigmentosa and other imperfections of body and of mind. A single case was reported by Bartolotti in 1914, with adiposogenital dystrophy, retinitis pigmentosa and polydactyly. He suggested that there was a premature synostosis of the basisphenoid, causing an abnormal influence on growth of the primordial hypophysis.

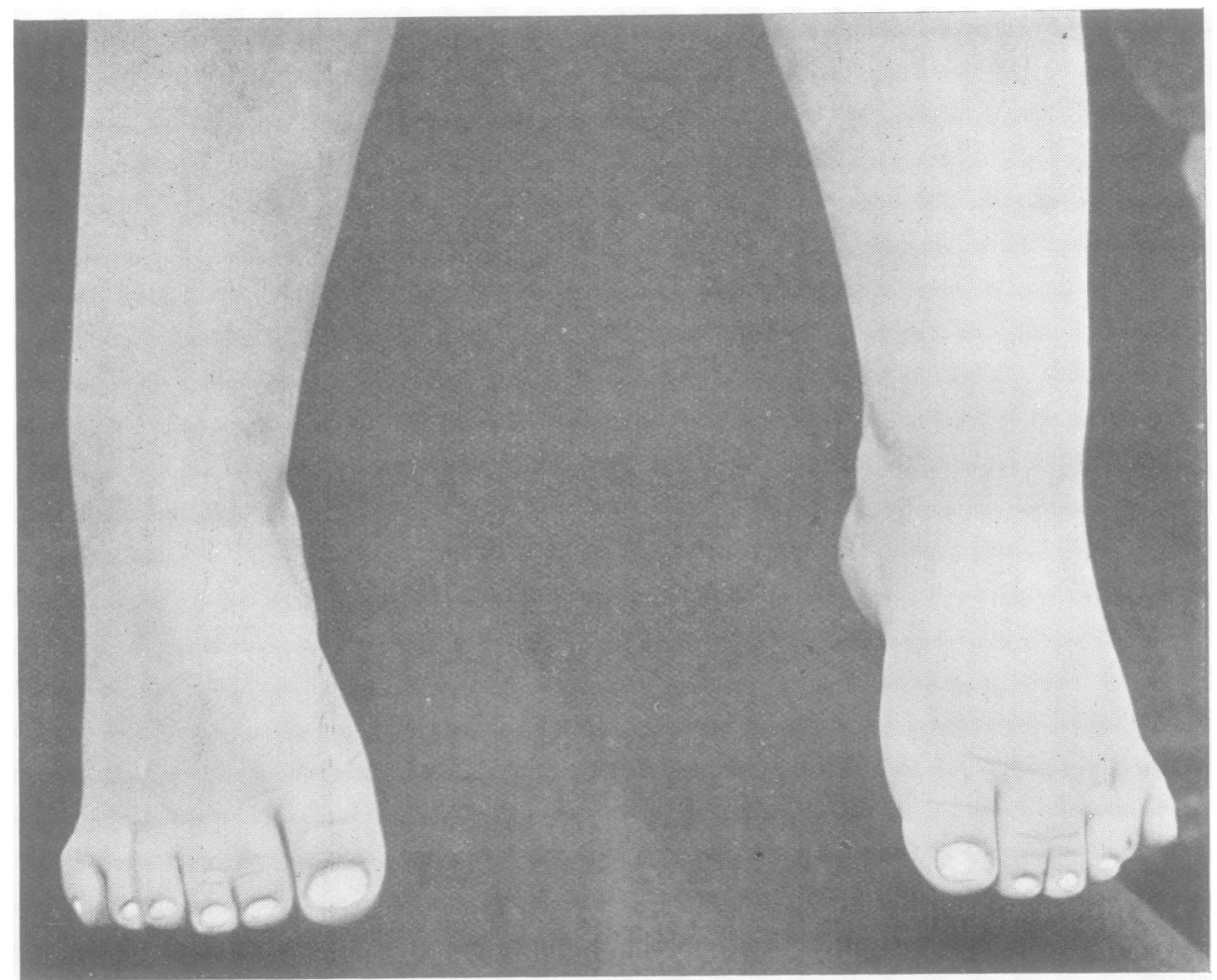

Bardet in 1920 described a typical case, collecting others more or less complete. He considered the whole syndrome to be due to a pituitary alteration occurring during the embryonic period, attributing to the anterior pituitary the control of the skeletal development of the extremities, on analogy with the bony changes of acromegaly, and referring to certain cases of polydactyly in which destruction of the pituitary had been found. In this connection we may mention Hastings Gilford's reference to Goliath's brother's son, and to other cases of gigantism with polydactyly. 
In 1922, Biedl described the syndrome as a new entity, separating it from Fröhlich's syndrome as one of a primary cerebral adiposity as distinct from a primary hypophyseal obesity. Raab, in his study of adiposity in 1924, described Biedl's cases and quoted others. He suggests an inborn tendency to the retinal condition, which usually develops sometime in childhood, and he remarks that adiposity often follows on acute illness. He regards the process as one of congenital malformation of the skeletal system with a tendency to internal hydrocephalus, causing pressure on the diencephalic metabolic centres, and impairment of the vascular supply to the retina. However, he also considers the possibility of an abnormally shaped dorsum sellæ interfering with the secretory pathways from the pituitary body to the third ventricle, thus acknowledging a possible, though perhaps secondary role to the pituitary in the production of the syndrome.

In 1925 , Solis-Cohen and Weiss described four cases in a family (strangely, most of the American cases seem to be in families of Italian origin). They made metabolic studies with anomalous results, and they follow Raab's theories of causation. They gave the syndrome the names of Lawrence and Biedl. Rieger and Trauner, in their study of a case, base a theory of causation on the known heredofamilial character of several of the symptoms, seeing in it the coupling of various inborn factors. In their case there was consanguinity, but this is unusual. Cases have been described more or less fully by several other writers.

In this syndrome we evidently have a heredofamilial tendency to developmental errors which arise in the earliest period of intrauterine life. Whether the error can be wholly attributable to the pituitary or to diencephalic centres is doubtful ; in any case its influence is progressive, as some of the symptoms may not appear till later, up to the tenth or fifteenth year. In favour of a pituitary implication we have the anomalies in height. In older subjects dwarfism is marked (six cases out of eight) but in those under 16 we have eleven tall to five dwarfed. This would suggest a preliminary overactivity of the growth-promoting hormone of the pituitary, with later deficiency. Genital dysplasia is usual but not invariable. Glucose tolerance has been found increased or diminished in about equal numbers. Polyuria has been noted rarely. A positive thermic reaction, diminished B.M.R., and a relative lymphocytosis may be evidences of pituitary dysfunction, but the interpretation of these metabolic findings is open to question. The Wassermann reaction is negative in the 16 cases in which it has been recorded.

The retinal condition is usually described as an atypical retinitis pigmentosa ; often there is also some optic atrophy, cataract, squint or nystagmus. Hemeralopsia is usual. There is no evidence of tumour (except in Bartolotti's case) or of definite hydrocephalus. The sella is usually small or normal in size with a thick or high dorsum, which has been invoked as a causal factor in the interference with neurohypophyseal mechanisms. The mental torpor might hypothetically be associated with the sleep centres round the third ventricle, which area is credited by some with the control of fat and sugar metabolism. 
The further study of this syndrome may give useful help in solving these problems of growth and metabolism.

I owe my grateful thanks to the Medical Superintendent, Dr. W. F. Menzies, for permission to publish this case.

\section{REFERENGES.}

Lawrence and Moon, Ophthalmic Review, 1866, ii, 32.

Bertolottr, Nouv. Icon. de la Salpêtr., 1914-5, xxvii, 11.

Madigan and Moore, Jour. Amer. Med. Assoc., 1918, lxx, 669.

Rozabal Farnes, Rev. neurol., 1913, xxvi, 439.

VAriot and Bouquier, Gaz. des $h \delta p$., 1920, xciii, 613.

Bardet, Thèse de Paris, 1920.

BIEDL, Deut. med. Woch., 1922, xlviii, 1530.

De Schweinitz, Trans. Ophth. Soc., 1923, xliii.

RAAB, Arch.f. inn. Med., 1924, vii, 443.

Denzler, Jahr. $f$. Kinderheilk., 1924-5, cvii, 35.

Deusch, Deut. Zeits.f. Nervenheilk., 1925, lxxxvii, 117.

Solis-Cohen and Weiss, Amer. Jour. Med. Sci., 1925, cxvi, 489.

McAlpine, Proc. Roy. Soc. Med., 1925.

Bernhardt, Zeits. f. klin. Med., 1928, cvii, 489.

BECK, Endocrinology, 1929, xiii, 375.

LISSER, Endrocrinology, 1929, xiii, 535.

Rieger and Trauner, Zeits. f. Augenheilk., 1929, lxviii, 235.

Boenheim, Endokrinologie, 1929, iv, 263.

StERLING, Rev. neurol., 1930, xxxvii, 661.

Gilford, Disorders of Post-natal Growth and Development, 1911, 493. 